\title{
Recurrent Thyroid Gland Follicular Carcinoma
}

National Cancer Institute

\section{Source}

National Cancer Institute. Recurrent Thyroid Gland Follicular Carcinoma. NCI Thesaurus.

Code C153622.

The reemergence of thyroid gland follicular carcinoma after a period of remission. 